\title{
Influence of pore water salinity on the compressibility of Maryland clay
}

\author{
Shengyang Yuan ${ }^{\text {i) }}$, Xianfeng Liu ${ }^{\text {ii) }}$ and Olivier Buzzi iii)
}

\begin{abstract}
i) Associate Professor, Key Laboratory of High-speed Railway Engineering of Ministry of Education, School of Civil Engineering, Southwest Jiaotong University, Chengdu, P. R. China, and Research Associate, Priority Research Centre for Geotechnical Engineering and Science, The University of Newcastle, Callaghan, NSW, 2308, Australia.

ii) Professor, Key Laboratory of High-speed Railway Engineering of Ministry of Education, School of Civil Engineering, Southwest Jiaotong University, Chengdu, P. R. China

iii) Professor, Priority Research Centre for Geotechnical Science and Engineering, The University of Newcastle, Callaghan, NSW, 2308, Australia.
\end{abstract}

\begin{abstract}
This experimental study investigates the compaction behavior of Maryland clay with different pore water salinity. Maryland clay powder was prepared with deionized water and $\mathrm{CalCl}_{2}$ solutions prepared at two concentrations $\left(0.1 \mathrm{M} / \mathrm{L} \mathrm{Ca}^{2+}\right.$ and $\left.1.0 \mathrm{M} / \mathrm{L} \mathrm{Ca}^{2+}\right)$ and then statically compacted in an oedometer cell. The compaction tests were complemented by microstructural characterization using mercury intrusion porosimetry. The effect of pore water salinity on the compaction behavior of the ML clay is quantified at both micro and macro scales. Results show that the compression index from 1D compression tests and the pore size distribution inferred by MIP are highly dependent on both the water content and pore water salinity. The compression index increases with water content but is not uniquely correlated with pore water salinity at a given water content. At low water contents, pore water salinity mainly affects the macro pores, while it leads to a significant influence on the micro pores when increasing water content.
\end{abstract}

Keywords: expansive soil, microstructure, compaction behaviour, pore water salinity

\section{INTRODUCTION}

In geo-environmental engineering, compacted active soils are often used as the clay barriers and clay liners to avoid contamination associated to migration of wastewater. The microstructure of compacted active soils plays a key role for the performance of clay barriers. Active soils are very sensitive to the chemical composition of pore water (Musso et al., 2013), as shown by Rao and Thyagaraj (2007) specimens exposed to larger osmotic suction gradients were expected to experience larger osmotic consolidation strains.
To date, not many studies have investigated the post compaction pore structure of active clays when prepared with different pore water chemical composition. In this study, the effect of pore water salinity on the compaction behavior of Maryland clay has been carried out at macro and micro levels. The evolution of void ratio and suction with the application of net stress was analyzed in light of pore size distribution obtained by mercury intrusion porosimetry (MIP) tests. 


\section{MATERIALS AND EXPERIMENTS}

\subsection{Materials}

The natural expansive soil used in this study was taken from the test site of the University of Newcastle, located at Maryland, NSW. It contains $10 \%$ (in mass) of illinite-smectite mixture layers. The liquid limit and plastic limit are $69.8 \%$ and $24.1 \%$, respectively. For more details please see Liu et al. (2016) and Yuan et al. (2016).

Oven dried $\left(105^{\circ} \mathrm{C}\right)$ natural soils were crushed to particles smaller than $1.18 \mathrm{~mm}$. Soil powders were mixed with deionized water content and $\mathrm{CaCl}_{2}$ (with concentration $0.1 \mathrm{M} / \mathrm{L}$ and $1 \mathrm{M} / \mathrm{L}$ ) to different target water contents, as presented in table 1 . Soils were left in air tight bags for two weeks to reach moisture equilibrium. Following the equilibrium phase, the soil was compacted in an oedometer ring, $19 \mathrm{~mm}$ in height and $45 \mathrm{~mm}$ in diameter, at a rate of $0.5 \mathrm{~mm} / \mathrm{min}$.

Suction was measured using a dewpoint potentiameter (model WP4C, Decagon) for moisture content below $20 \%$ while for the wetter specimens, a high capacity tensiometer (HCT, capacity of 1.5 MPa) was used, see Mendes and Buzzi (2013). Note that the WP4C was calibrated using $\mathrm{NaCl}$ and $\mathrm{KCl}$ solutions at different concentration. The samples prepared with deionized water were found to have suction of $\sim 9.3$ $\mathrm{MPa}, \sim 0.8 \mathrm{MPa}$ and $\sim 0.2 \mathrm{MPa}$ for water contents of $11.8 \%, 21.0 \%$ and $28.1 \%$, respectively. The suction for samples prepared with $\mathrm{CaCl}_{2}$ was presented in table 1. The total suction of $\mathrm{CaCl}_{2}$ with concentration $1 \mathrm{M} / \mathrm{L}$ and $0.1 \mathrm{M} / \mathrm{L}$ are $8.82 \mathrm{MPa}$ and $0.57 \mathrm{MPa}$, respectively.

Table 1 Initial water contents and post compaction suction of compacted samples

\begin{tabular}{|c|c|c|c|}
\hline \multirow{2}{*}{} & $\begin{array}{c}\text { De- } \\
\text { ionized } \\
\text { water }\end{array}$ & $\begin{array}{c}0.1 \mathrm{M} \\
\mathrm{CaCl}_{2}\end{array}$ & $\begin{array}{c}1 \mathrm{M} \\
\mathrm{CaCl}_{2}\end{array}$ \\
\hline $\begin{array}{c}\text { Water content- } \\
\%\end{array}$ & $11.8(9.3)$ & $\begin{array}{c}12.2 \\
(10.57)\end{array}$ & $\begin{array}{c}11.4 \\
(20.69)\end{array}$ \\
\cline { 2 - 4 } $\begin{array}{c}\text { with the } \\
\text { suction-MPa in } \\
\text { bracket }\end{array}$ & $21.0(0.8)$ & $\begin{array}{c}22.3 \\
(1.58)\end{array}$ & $\begin{array}{c}21.4 \\
(11.67)\end{array}$ \\
\cline { 2 - 4 } & $28.1(0.2)$ & $\begin{array}{c}29.5 \\
(0.719)\end{array}$ & $\begin{array}{c}28.6 \\
(10.29)\end{array}$ \\
\hline
\end{tabular}

Note that the value in the bracket is the corresponding post compaction suction at specific water content.

\subsection{Experiments}

The one-dimensional static compaction cell presented in Yuan et al. (2018) was used in this study. For a matter of space, the apparatus is not described here. Samples with initial water content given in table 1 have been compacted to a target void ratio of $\sim 0.8$.

MIP tests have been carried out for all the compacted samples using a Micromeritics AutoPore IV 9500. The samples were prepared by freeze-drying, priori to mercury intrusion, in order to remove water with little structural changes.

\section{RESULTS}

\subsection{Evolution of void ratio with net stress}

The evolution of void ratio with vertical net stress is presented in Figure 1 for samples prepared with different pore water salinity. For each pore water composition, it can be observed that, as water content increases, the compressibility of sample increases. This response is consistent with previous studies in the literature (Alonso et al., 1990). No notable difference is observed between the different moisture contents along the unloading path. The effect of pore water salinity on the compressibility of Maryland clay is given in Figure 1 (d). For the compression index $\left(\mathbf{C}_{\mathrm{c}}\right)$, the effect of pore water salinity changes as water content increases. For the lowest water content, the compression index for sample prepared with $1 \mathrm{M} / \mathrm{L} \mathrm{CaCl}_{2}$ is larger than the others two. The compression indices of samples prepared with $0.1 \mathrm{M} / \mathrm{L} \mathrm{CaCl}_{2}$ and de-ionized water are almost equal.

At a water content of $22 \%$, the three specimens have the same compression index. At a water content of $28 \%$, it is the specimen prepared with deionized water that has the highest compression index. Finally, the effect of pore water salinity and water content on the recompression index is very small. With highest recompression index for specimens prepared with $0.1 \mathrm{M} / \mathrm{L} \mathrm{CaCl}_{2}$ and smallest recompression index for specimens prepared with $1 \mathrm{M} / \mathrm{L} \mathrm{CaCl}_{2}$. 

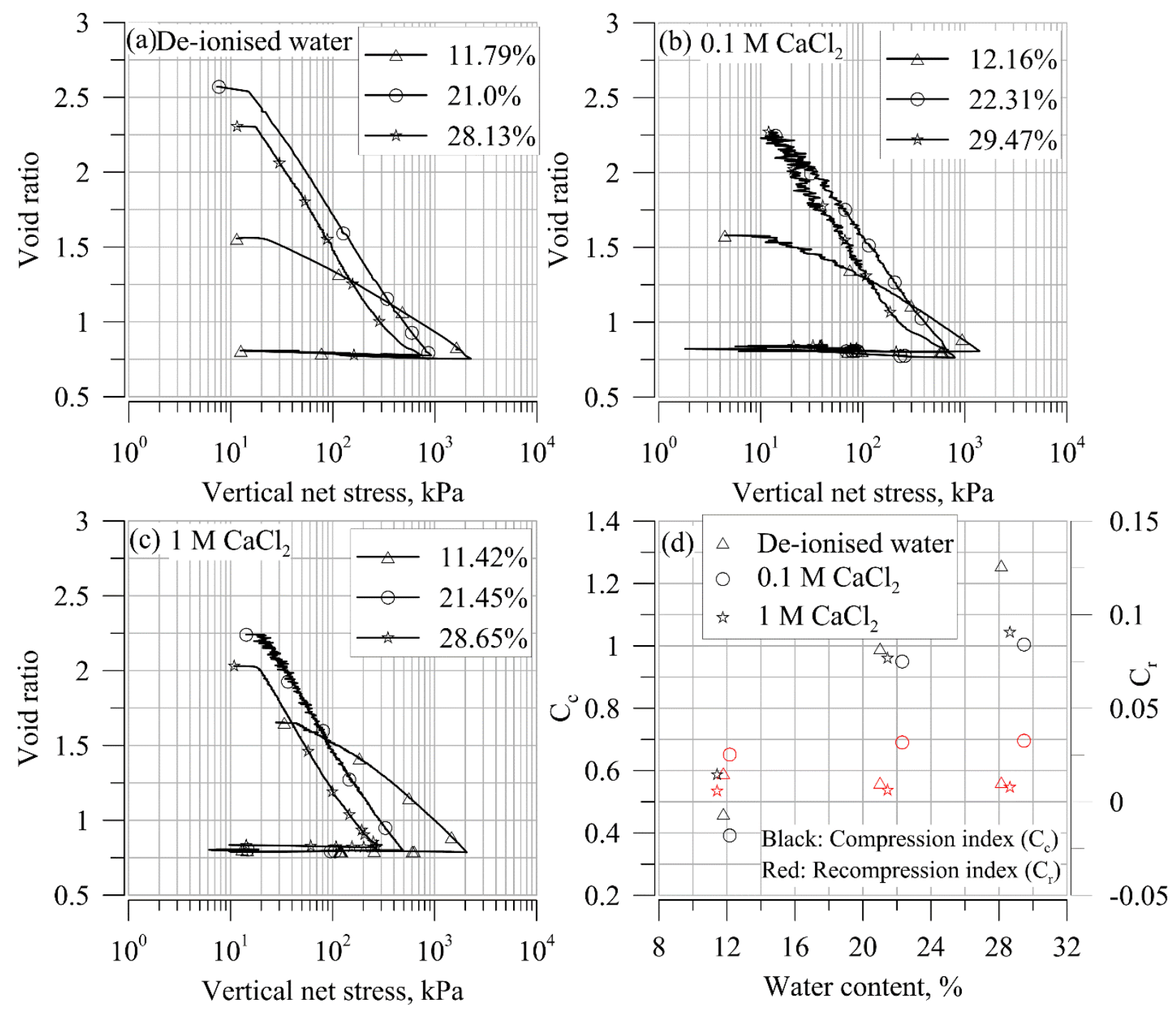

Fig. 1 Evolution of void ratio with vertical net stress of Maryland clay prepared with solution with different salinity concentration: (a) de-ionized water; (b) $\mathrm{CaCl}_{2} 0.1 \mathrm{M} / \mathrm{L}$ and (c) $\mathrm{CaCl}_{2} 1 \mathrm{M} / \mathrm{L}$. (d) Compression and recompression index for Maryland clay prepared with different pore water. Note that $\mathrm{Cc}$ stands for compression index, and $\mathrm{Cr}$ stands for recompression index.

It is generally understood that pore water salinity will constrain aggregate swelling, which leads to the aggregation of soil particle (Stawinski et al., 1990). This effect is exacerbated at high concentrations. It is also recognized that, as the water content of expansive clay increases, swelling is observed. As such, the combined effect of salt solution and water content govern the compressibility of compacted reactive clays. At lower water content, the effect of salt concentration is predominant, but it gradually decreases as water content increases. At high water content, the effect of water prevails over that of salinity.

\subsection{Microstructure evolution}

The pore size distributions for all samples are shown in Figure 2. Regardless of the pore water chemistry, all specimens display a bi-modal distribution of pores, except for the highest water content. As water content augments, both dominant pore size and corresponding density for the micro pore $\left(\mathrm{P}_{\mathrm{m}}\right)$ are observed to increase. This is a known behavior that is explained by aggregate swelling. The trend is slightly different for the macro pores: while the dominant pore size increases, the corresponding density is observed to reduce. 


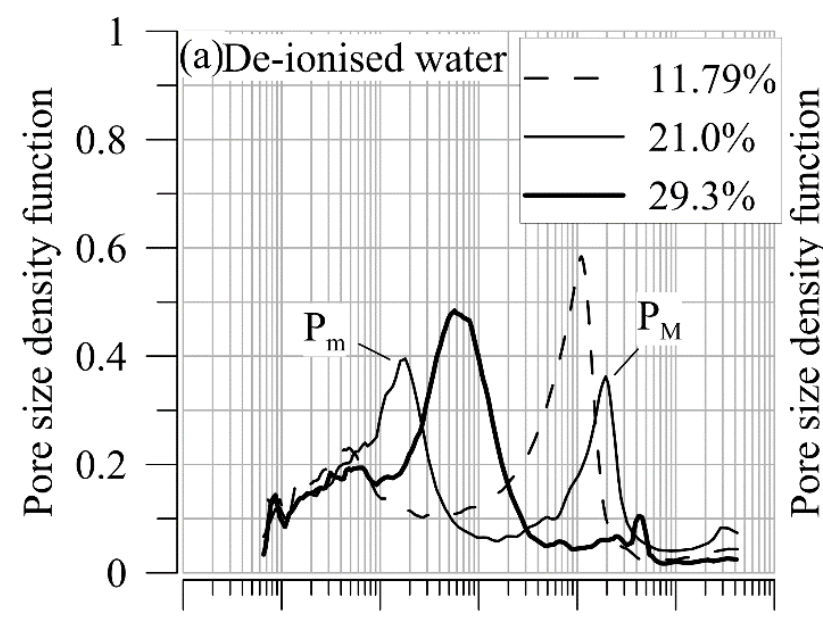

$$
\begin{array}{lllllll}
10^{-3} & 10^{-2} & 10^{-1} & 10^{0} & 10^{1} & 10^{2} & 10^{3}
\end{array}
$$

Entrance pore diameter, $\mu \mathrm{m}$

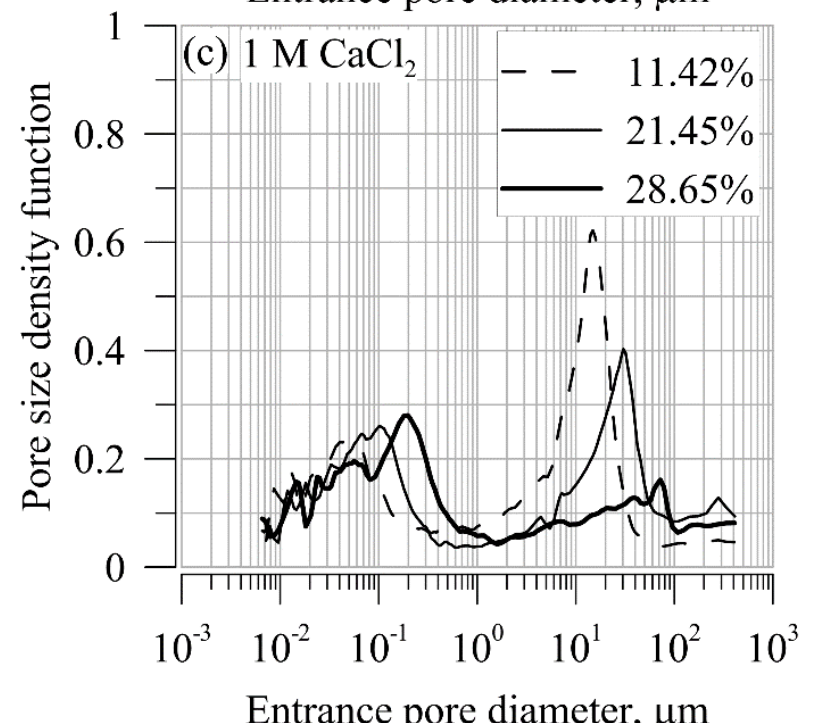

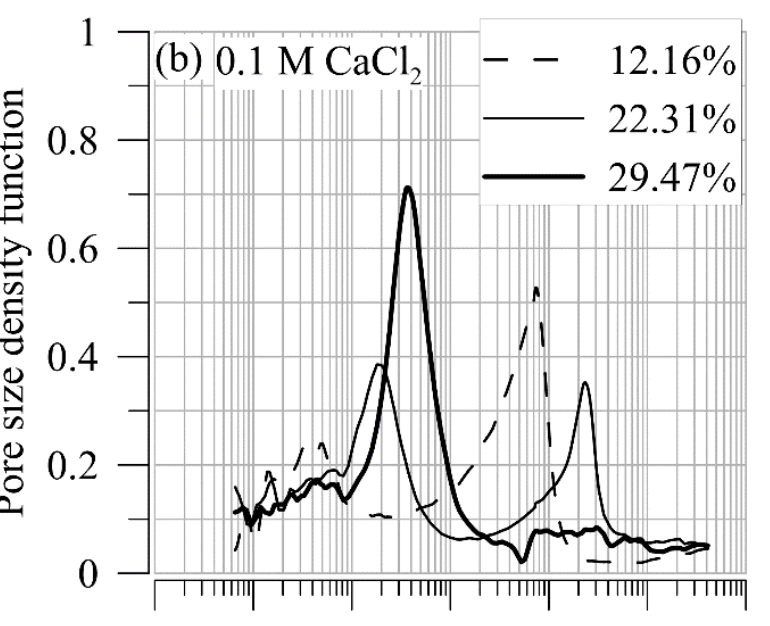

$\begin{array}{lllllll}10^{-3} & 10^{-2} & 10^{-1} & 10^{0} & 10^{1} & 10^{2} & 10^{3}\end{array}$

Entrance pore diameter, $\mu \mathrm{m}$

Fig. 2 Pore size distribution of compacted Maryland clay prepared with solution with different salinity concentration: (a) de-ionized water; (b) $\mathrm{CaCl}_{2} 0.1 \mathrm{M} / \mathrm{L}$ and (c) $\mathrm{CaCl}_{2} 1 \mathrm{M} / \mathrm{L}$.

Figure 2 is then replotted to highlight the effect of pore water salinity on the pore size distribution at specific water content (Figure 3). Under the lowest values of water content, the micro pore fraction is very similar for all samples and the main difference lies within the macro pore fraction. The sample prepared with $1 \mathrm{M} / \mathrm{L} \mathrm{CaCl}_{2}$ has the largest size of dominant macro pore, followed by samples prepared with de-ionized water and $0.1 \mathrm{M} / \mathrm{L} \mathrm{CaCl}_{2}$. This is here explained by the aggregation of clay particles, which is much higher under a $\mathrm{CaCl}_{2}$ concentration of $1 \mathrm{M} / \mathrm{L}$. Larger aggregates correspond to larger macro pores.

Interestingly, the order of macro pore size is consistent with the order of compression indices shown in Figure 1 (d). The soil with the largest compression index (corresponding to a pore water salinity of $1 \mathrm{M} / \mathrm{L} \mathrm{CaCl}_{2}$ ) is the one having the highest compressibility, which makes sense since the compression of the soil leads to a reduction in macro pores. 

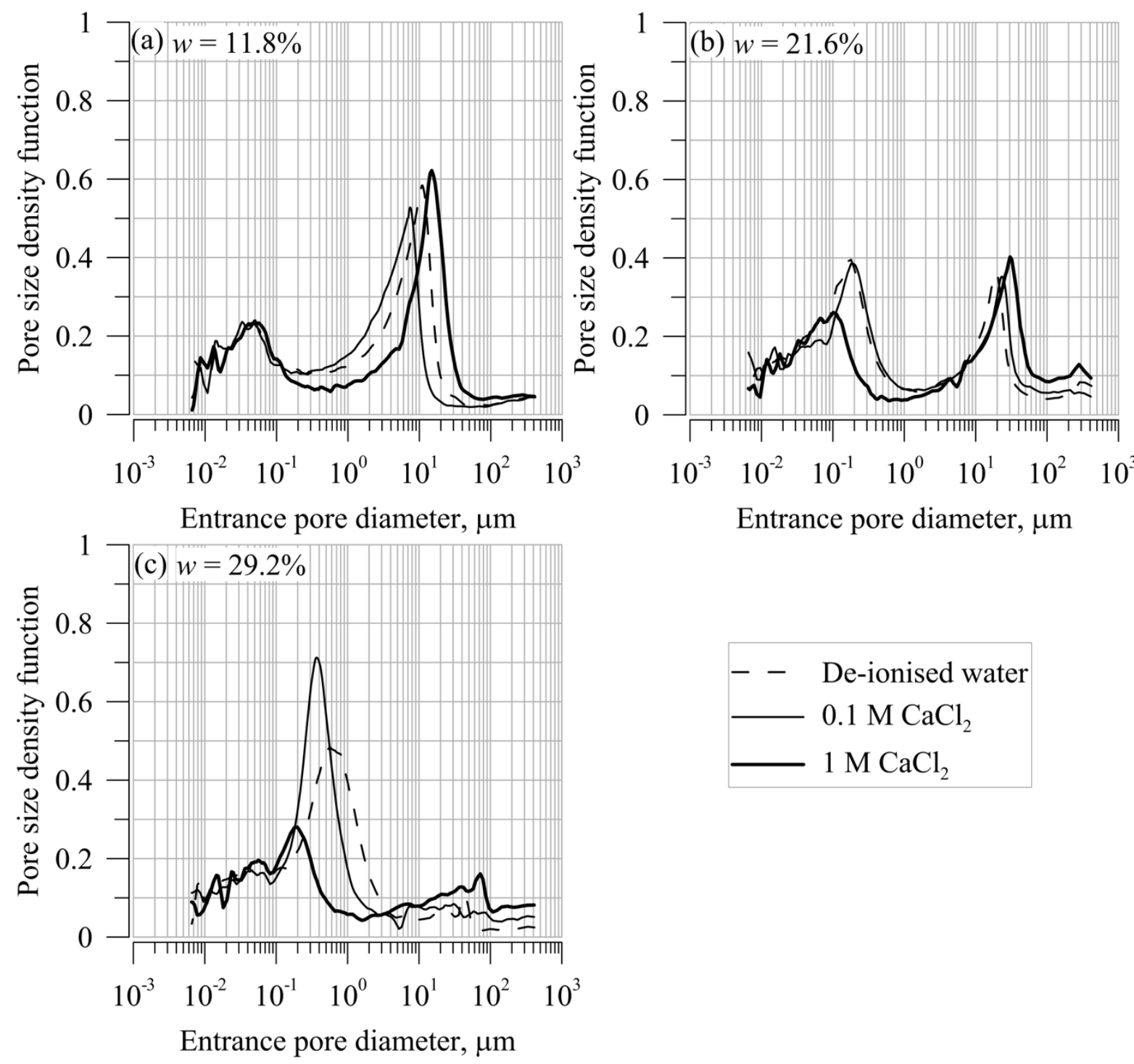

Fig. 3 Effect of pore solution on the pore size distribution of compacted Maryland clay: (a) water content 11.8\%; (b) water content $\sim 21.6 \%$ and (c) water content $\sim 29.2 \%$.

As the water content increases to $21.6 \%$, the pore size distributions of samples prepared with 0.1 $\mathrm{M} / \mathrm{L} \mathrm{CaCl}_{2}$ and de-ionized water are almost the same. For the sample prepared with $1 \mathrm{M} / \mathrm{L} \mathrm{CaCl}_{2}$, the effect of pore water salinity on the micro pores is very clear, the dominant pore size and density of micro pore is much smaller than the others two. High concentration of $\mathrm{CaCl}_{2}$ seems to slightly hinder swelling of the aggregates. Meanwhile, the effect of highest salinity ( $1 \mathrm{M} / \mathrm{L})$ only seems to affect pore size but not density. The similarity of macro pore sizes leads to similar compression index for the samples.

For the highest water content, $29.2 \%$, all pore size distributions are seen to become mono-modal, and the main effect of pore water salinity pertains to the dominant pore size. The dominant pore size is found to become larger as the salinity reduces. Note that there is no clear trend to explain the effect of salinity on pore density. This behavior is likely due to the fact that the non-intruded pore volume is much larger for the sample prepared with $1 \mathrm{M} / \mathrm{L}$ $\mathrm{CaCl}_{2}$, as shown in Figure 4. Similar results were obtained by Manca et al. (2016). As the dominant 
pore size of sample prepared with de-ionized water is larger than the others two, the compression index is also larger than the others two (see Figure 1(d)). Even though the dominant pore size of sample prepared with $0.1 \mathrm{M} / \mathrm{L} \mathrm{CaCl}_{2}$ is larger than that of 1 $\mathrm{M} / \mathrm{L} \mathrm{CaCl}_{2}$, the compression index shown in Figure 1 are almost the same, this might due to the small peak of sample prepared with $1 \mathrm{M} / \mathrm{L} \mathrm{CaCl}_{2}$ around 7 micrometer entrance pore diameter.

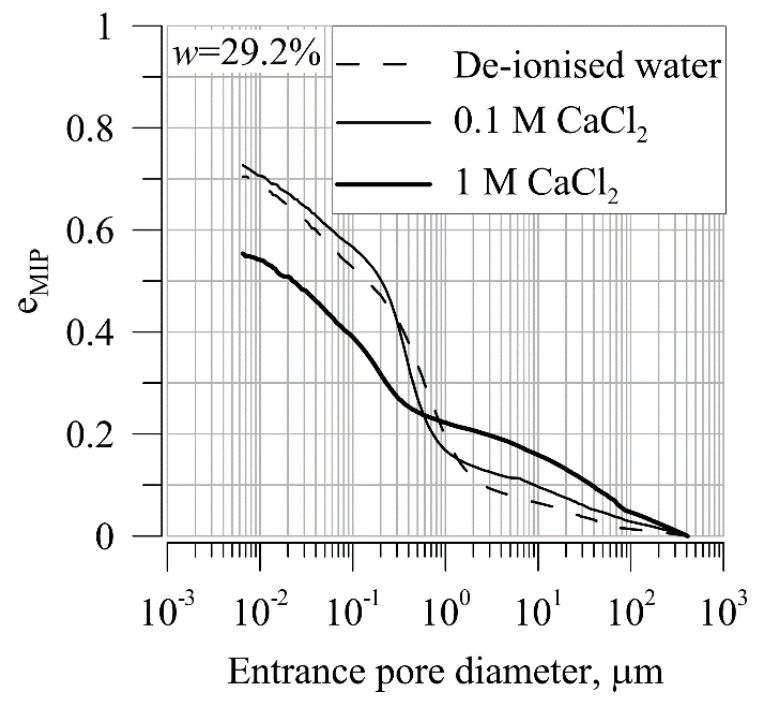

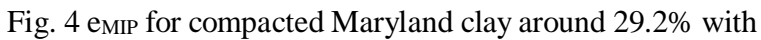
three different pore water solution.

\section{CONCLUSIONS}

In this study, the compressibility of Maryland clay prepared with different pore water salinity (deionized water, $0.1 \mathrm{M} / \mathrm{L} \mathrm{CaCl}_{2}$ and $1 \mathrm{M} / \mathrm{L} \mathrm{CaCl}_{2}$ ) was studied by a series of quasi-static compaction tests and microstructural investigations. The specimens were prepared at different moisture content and it was found that the combined effect of suction and pore water salinity govern the soil response. The compressibility was correlated to the macro pore fraction of the compacted samples: the more the macro pores, the more compressible the soil.

\section{ACKNOWLEDGEMENTS}

The authors would like to express their gratitude to the Australian Research Council (ARC) for the financial support (ARC DP110103304). The support from the China Scholarship Council (CSC) is also gratefully acknowledged.

\section{REFERENCES}

1) Alonso, E.E., Gens, A., Josa, A., 1990. A constitutive model for partially saturated soils. Géotechnique 40, 405-430. https://doi.org/10.1680/geot.1990.40.3.405

2) Liu, X.F., Buzzi, O., Yuan, S., Mendes, J., Fityus, S., 2016. Multi-scale characterization of the retention and shrinkage behaviour of four Australian clayey soils. Can. Geotech. J. 53, 854-870.

3) Manca, D., Ferrari, A., Laloui, L., 2016. Fabric evolution and the related swelling behaviour of a sand/bentonite mixture upon hydro-chemo-mechanical loadings. Geotechnique, 66(1), 41-57.

4) Mendes, J., Buzzi, O., 2013. New insight into cavitation mechanisms in high-capacity tensiometers based on high-speed photography. Can. Geotech. J. 556, 550-556.

5) Musso, G., Romero, E., Della Vecchia, G., 2013. Doublestructure effects on the chemo-hydro-mechanical behavior of a compacted active clay. Geotehonique, 63 (3), 206-220.

6) Rao, S. M. \& Thyagaraj, T. (2007). Swell-compression behaviour of compacted clays under chemical gradients. Can. Geotech. J. 44, No. 5, 520-532.

7) Stawinski, J., Wierzchos, J., Garcia-Gonzalez, M., 1990. Influence of Calcuim and sodium concentration on the microstructure of bentonite and kaolin. Clays and Clay Minerals, 38(6), 617-622.

8) Yuan, S., Liu, X., Buzzi, O., 2018. Structure of compacted Maryland clay and suction profiles. 2018 World Transport Convention, Beijing, China, 1-10.

9) Yuan, S., Liu, X., Sloan, S.W., Buzzi, O.P., 2016. Multiscale characterization of swelling behaviour of compacted Maryland clay. Acta Geotech. 11, 789-804. 